\title{
Research and Application of Molecular and Phenotypic Data for Tree Biodiversity Evaluation
}

\author{
Gaetano Distefano
}

check for

updates

Citation: Distefano, G. Research and Application of Molecular and Phenotypic Data for Tree Biodiversity Evaluation. Forests 2021, 12, 564. https://doi.org/10.3390/f12050564

Received: 14 April 2021

Accepted: 25 April 2021

Published: 30 April 2021

Publisher's Note: MDPI stays neutral with regard to jurisdictional claims in published maps and institutional affiliations.

Copyright: (C) 2021 by the author. Licensee MDPI, Basel, Switzerland. This article is an open access article distributed under the terms and conditions of the Creative Commons Attribution (CC BY) license (https:/ / creativecommons.org/licenses/by/ $4.0 /)$.
Department of Agriculture, Food and Environment, University of Catania, Via Valdisavoia 5, 95123 Catania, Italy; distefag@unict.it

The main challenges for tree crop improvement are linked to the sustainable development of agro-ecological habitats, improving the adaptability to limiting environmental factors and resistance to biotic stresses or promoting novel genotypes with improved agronomic traits.

The exploitation of plant genetic resources and their conservation and sustainable management are the key to guaranteeing environmental and food security for future generations, since this will determine the ability of crops to adapt in several conditions. Significant advances in the application of molecular tools to characterize and conserve genetic diversity in tree crops took place in the last decades.

Molecular marker technologies are being increasingly used to explore genetic structure and function, and to provide high-resolution profiling of nucleotide variation within tree crop germplasm collections. Advances in DNA-derived data and innovative phenotyping are bridging the genotype-to-phenotype gap in tree crop selection.

In this Special Issue, fourteen original articles and one review represent a brief overview of the latest genetic and phenotypic trait characterization for tree crop.

Genetic characterization of different tree crops was performed by studying S-allele segregation, epi-markers, and molecular markers.

The study by Bennici et al. [1] was conducted on Italian pear germplasm collection (Pyrus communis) composed of varieties selected across the last two centuries, for their traits of agronomic interest and was complemented with wild related species (P. pyrifolia, $P$. amygdaliformys), for the S-allele genotyping. The results shaded light on the differences between the traditional varieties, with the wild-related species reflecting a more complex history of hybridization.

Tuisima-Coral et al. [2] used the amplified fragment length polymorphic (AFLP) fingerprints to estimate the genetic diversity of Guazuma crinita, a fast-growing timber tree species. The analysis of molecular variation showed higher genetic diversity within rather than among provenances. Cluster analysis and principal coordinate analysis did not show correspondence between genetic and geographic distance and significant genetic differentiation among population types.

Ma et al. [3] detected epimarkers using a methylation-sensitive amplification polymorphism (MSAP) method and performed epimarker-trait association analysis on the basis of nine growth and wood property traits within populations of 432 genotypes of Populus tomentosa. Tree height was positively correlated with relative full-methylation level, suggesting that changes in DNA methylation might contribute to regulating tree growth and wood property traits.

The study by Rollo et al. [4] assessed the genetic diversity and structure of the icecream-bean (Inga edulis Mart.; Fabaceae) in wild and cultivated populations from the Peruvian Amazon. The average pod length in cultivated trees was significantly higher than that in wild trees. The expected genetic diversity and the average number of alleles was higher in the wild compared to the cultivated populations; thus, a loss of genetic diversity was confirmed in the cultivated populations. 
Lee et al. [5] characterized 410 tea accessions collected from South Korea, using 21 simple sequence repeat (SSR) markers. The study revealed the presence of lower diversity and a simpler population structure in Korean tea germplasms. Suggesting, more attention on collecting and conserving the new tea individuals, to broaden the genetic variation of new cultivars in future breeding of the tea plant.

Particular interest was paid to the novel sequencing method of plastid genome combined with molecular markers or phenotypic traits for several forest tree species as a tool to better define the genetic phylogenies and domestication process.

In particular, Su et al. [6] studied the different phenotypic traits of four endemic Ilex species (I. latifolia, I. suaveolens, I. viridis, and I. micrococca) on Mount Huangshan, China. A comprehensive comparison of plastomes within eight Ilex revealed the incongruence with the traditional taxonomy, whereas it informed a strong association between clades and geographic distribution.

Zeng et al. [7] used chloroplast DNA sequences and 29 nuclear microsatellite markers to investigate $C . \times$ kuchugouzhui (natural hybrid between $C$. sclerophylla and C. tibetana) confirming that it is a rare hybrid between C. sclerophylla and C. tibetana.

The study by Guo et al. [8] was based on the first collection of cultivated Paeonia rockii (flare tree peony, FTP) germplasm, across the main distribution area. Using phenotypic traits, expressed sequence tag (EST)-simple sequence repeat (SSR) markers and chloroplast DNA sequences (cpDNA), the authors showed that the selected accessions could fully reflect the genetic background information of FTP germplasm resources, so their protection and utilization would be of great significance for genetic improvement of woody peonies.

Deng et al. [9] carried out two different studies on Michelia shiluensis (Magnoliaceae), a rare and endangered magnolia species found in South China. The first study was dedicated to examining the genetic diversity of M. shiluensis, in which high genetic diversity and low differentiation were detected using eight nuclear single sequence repeat (nSSR) markers, and two chloroplast DNA (cpDNA) markers.

The second study relied on the complete chloroplast genome sequencing of M. shiluensis [10]. The genetic structure was represented by 160,075 bp in length with two inverted repeat regions (26,587 bp each), a large single-copy region (88,105 bp), and a small copy region $(18,796 \mathrm{bp})$. The genomic information presented in this study was valuable for further classification, phylogenetic studies, and to support ongoing conservation efforts.

Yu et al. [11] reported the complete chloroplast genomes of five species of Acer sect. Platanoidea. The length of Acer sect. Platanoidea cp genomes ranged from 156,262 bp to $157,349 \mathrm{bp}$ and detected the structural variation in the inverted repeat (IRs) boundaries. Platanoidea, with high resolutions for nearly all identified nodes, suggests a promising opportunity to resolve infrasectional relationships of the most species-rich section Platanoidea of Acer.

On the other hand, phenotypic traits were evaluated to select improved individuals or traits.

The study by Kim et al. [12] was conducted to select plus trees of two evergreen oaks, Quercus salicina and Q. glauca, in Korea. To select the candidate trees, they developed a subjective grading system with six characteristics in three categories and introduced a weighted generalized value (GVIw) to compare the superiority of the candidate trees. Through this process, 44 candidate trees of Q. salicina and 41 candidate trees of Q. glauca were selected as plus trees.

The study by Baniulis et al. [13] monitored the constitutive protein expression differences detected during active growth associated with cell metabolism and stress response, and conveyed a population-specific adaptation to the distinct climatic conditions in geographically distant Scots pine (Pinus sylvestris L.) populations adapted to specific photoperiods and temperature gradients, and which markedly vary in the timing of growth patterns and adaptive traits.

Dinulică et al. [14] measured the acoustic properties of wood for identifying simple, valid criteria for diagnosis, which remains an exciting challenge when selecting materials 
for manufacturing musical instruments. The results showed that the spruce trees with acoustic and structural features that match the requirements for the manufacture of violins have a bark phenotype distinguishable by color-as well as by scale shape. The southfacing side of the trunk and the external side of the scale were best for identifying resonance trees by their bark. The authors concluded that the differences among bark phenotypes were noticeable to the naked eye.

Zhao et al. [15] monitored the leaf color mutation as ideal materials for studying pigment metabolism, chloroplast development and differentiation, photosynthesis, and other pathways that could also provide important information for improving varietal selection. In this review, the authors summarized the research on leaf color mutants, such as the functions and mechanisms of leaf color mutant-related genes, which affect chlorophyll synthesis, chlorophyll degradation, chloroplast development, and anthocyanin metabolism. The review provides a reference for the study and application of leaf color mutants in the future.

This Special Issue end points were to contribute to the growth of this area of research, trigger research interest on biodiversity conservation, and valorization, by adding genetic and phenotypic information scientifically substantiated with new data.

We would like to thank all authors and reviewers of the papers published in this Special Issue for their great contributions and efforts. We are also grateful to the editorial board members and to the staff of the Journal for their kind support in the preparation steps of this Special Issue.

Funding: This research received no external funding.

Informed Consent Statement: Not applicable.

Conflicts of Interest: The author declares no conflict of interest.

\section{References}

1. Bennici, S.; Di Guardo, M.; Distefano, G.; Las Casas, G.; Ferlito, F.; De Franceschi, P.; Dondini, L.; Gentile, A.; La Malfa, S. Deciphering S-RNase Allele Patterns in Cultivated and Wild Accessions of Italian Pear Germplasm. Forests 2020, $11,1228$. [CrossRef]

2. Tuisima-Coral, L.L.; Hlásná Čepková, P.; Weber, J.C.; Lojka, B. Preliminary Evidence for Domestication Effects on the Genetic Diversity of Guazuma crinita in the Peruvian Amazon. Forests 2020, 11, 795. [CrossRef]

3. Ma, K.; Song, Y.; Ci, D.; Zhou, D.; Tian, M.; Zhang, D. Genome Cytosine Methylation May Affect Growth and Wood Property Traits in Populations of Populus tomentosa. Forests 2020, 11, 828. [CrossRef]

4. Rollo, A.; Ribeiro, M.M.; Costa, R.L.; Santos, C.; Clavo, P.Z.M.; Mandák, B.; Kalousová, M.; Vebrová, H.; Chuqulin, E.; Torres, S.G.; et al. Genetic Structure and Pod Morphology of Inga edulis Cultivated vs. Wild Populations from the Peruvian Amazon. Forests 2020, 11, 655. [CrossRef]

5. Lee, K.J.; Lee, J.-R.; Sebastin, R.; Shin, M.-J.; Kim, S.-H.; Cho, G.-T.; Hyun, D.Y. Assessment of Genetic Diversity of Tea Germplasm for Its Management and Sustainable Use in Korea Genebank. Forests 2019, 10, 780. [CrossRef]

6. Su, T.; Zhang, M.; Shan, Z.; Li, X.; Zhou, B.; Wu, H.; Han, M. Comparative Survey of Morphological Variations and Plastid Genome Sequencing Reveals Phylogenetic Divergence between Four Endemic Ilex Species. Forests 2020, 11, 964. [CrossRef]

7. Zeng, X.; Chen, R.; Bian, Y.; Qin, X.; Zhang, Z.; Sun, Y. Identification of a Natural Hybrid between Castanopsis sclerophylla and Castanopsis tibetana (Fagaceae) Based on Chloroplast and Nuclear DNA Sequences. Forests 2020, 11, 873. [CrossRef]

8. Guo, X.; Cheng, F.; Zhong, Y. Genetic Diversity of Paeonia rockii (Flare Tree Peony) Germplasm Accessions Revealed by Phenotypic Traits, EST-SSR Markers and Chloroplast DNA Sequences. Forests 2020, 11, 672. [CrossRef]

9. Deng, Y.; Liu, T.; Xie, Y.; Wei, Y.; Xie, Z.; Shi, Y.; Deng, X. High Genetic Diversity and Low Differentiation in Michelia shiluensis, an Endangered Magnolia Species in South China. Forests 2020, 11, 469. [CrossRef]

10. Deng, Y.; Luo, Y.; He, Y.; Qin, X.; Li, C.; Deng, X. Complete Chloroplast Genome of Michelia shiluensis and a Comparative Analysis with Four Magnoliaceae Species. Forests 2020, 11, 267. [CrossRef]

11. Yu, T.; Gao, J.; Huang, B.-H.; Dayananda, B.; Ma, W.-B.; Zhang, Y.-Y.; Liao, P.-C.; Li, J.-Q. Comparative Plastome Analyses and Phylogenetic Applications of the Acer Section Platanoidea. Forests 2020, 11, 462. [CrossRef]

12. Kim, I.S.; Lee, K.M.; Shim, D.; Kim, J.J.; Kang, H.-I. Plus Tree Selection of Quercus salicina Blume and Q. glauca Thunb. and Its Implications in Evergreen Oaks Breeding in Korea. Forests 2020, 11, 735. [CrossRef]

13. Baniulis, D.; Sirgeddienè, M.; Haimi, P.; Tamošiūnè, I.; Danusevičius, D. Constitutive and Cold Acclimation-Regulated Protein Expression Profiles of Scots Pine Seedlings Reveal Potential for Adaptive Capacity of Geographically Distant Populations. Forests 2020, 11, 89. [CrossRef] 
14. Dinulică, F.; Albu, C.-T.; Vasilescu, M.M.; Stanciu, M.D. Bark Features for Identifying Resonance Spruce Standing Timber. Forests 2019, 10, 799. [CrossRef]

15. Zhao, M.-H.; Li, X.; Zhang, X.-X.; Zhang, H.; Zhao, X.-Y. Mutation Mechanism of Leaf Color in Plants: A Review. Forests 2020, 11, 851. [CrossRef] 